\title{
Na combustão das imagens
}

\author{
lsabel Pinto Carlos
}

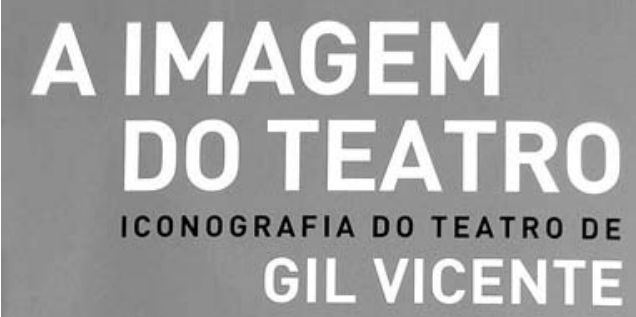

Situação análoga é testemunhada na carta do padre António da Costa, de 26 de Dezembro de 1558: "Ajudou muyto para estar a gente mais prompta estar o padre Marcos no meyo do teatro e declarar ao viso-rey o nome das figuras e o que tratavão" (Documentação

para a história das missões do padroado português do Oriente

India, Vol. VI, Lisboa, Fundação Oriente/CNCDP 1993, p. 457)

Levada pelo entusiasmo "documental" do autor, fui consultar os indices da Chancelaria de D. João III, onde encontrei o titulo Capela de Jesus no Convento da Trindade

de Lisboa: Contrato a

Vasco Fernandes (Livro III). Documentos como este, no caso de se tratar

de uma encomenda de arte, poderão conter dados sobre a maneira como o rei lidava com a produção artistica.

${ }^{3} 0$ Livro de

Vestiarias da Casa Real

trará certamente

aditamentos a esta questão (cf. Colecção S. Vicente, Livro II, fls. 252-

253, ANTT).

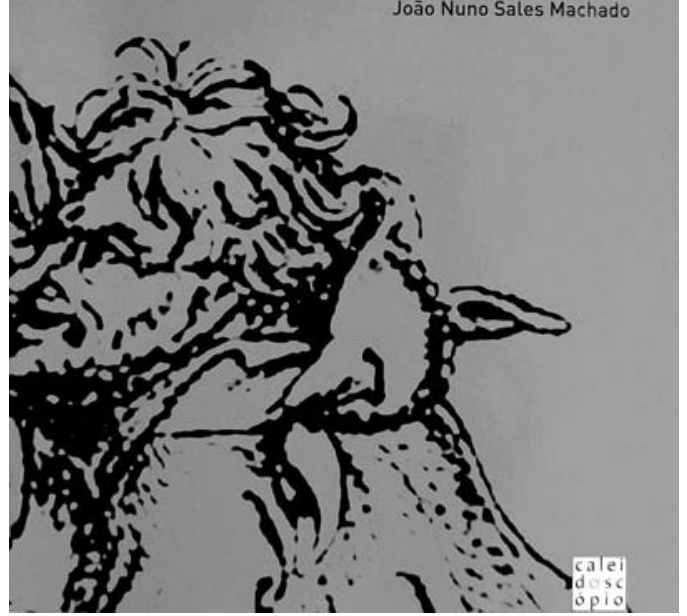

O livro, que remonta a uma dissertação de mestrado em Estudos de Teatro, apresentada à Faculdade de Letras da Universidade de Lisboa, em 2002, propõe uma abordagem do teatro de Gil Vicente que se exclui do "campo de estudos da literatura dramática" (p. 13) e se filia na tradição dos estudos iconográficos, inaugurada por Erwin Panofsky em Studies in lconology (1939), circunstância que o título reflecte mas a lombada confunde (cf. "Iconografia do Teatro de").

A obra divide-se em três capítulos: "Teatro, arte visual", "O universo imagético de Gil Vicente: Contexto artístico do teatro em Portugal no século XVI" e "As imagens e o teatro: Leitura iconológica de Breve sumário da história de Deos".

No primeiro, composto por duas secções, "Proximidade das artes" e "Iconografia teatral", assinala-se a letra dos autos como ponto de partida para chegar ao universo imagético vicentino, através de uma leitura interdisciplinar entre História do Teatro e História da Arte, pontuada pela consciência da ligação entre texto e espectáculo. É fazendo uso do primeiro para reconstituir as imagens próprias do segundo, à margem do debate acerca da condição do texto dramático, que a leitura iconológica dos textos de Gil Vicente, mormente História de Deos, deve ser vista neste estudo.
João Nuno Sales Machado, $A$ imagem do teatro. Iconografia do teatro de Gil Vicente, Casal de Cambra, Caleidoscópio, 2005, $221 \mathrm{pp}$.

0 segundo capítulo integra as seguintes secções: "0 Recebimento de 1521", "A procissão do Corpus Christi", "A política de imagem do rei", "A condição dos artistas", "Círculos de informação" e "A recepção das obras". No seu conjunto, caracterizam, de forma bastante completa, o contexto sócio-cultural de Gil Vicente, na encruzilhada entre o Manuelino, ou modo "moderno", e a crescente influência do "modo de Itália", própria do reinado de D. João III. Reconstituem-se, a partir da Crónica de Gaspar Correia, os festejos públicos do Recebimento a D. Manuel I e sua terceira mulher, Leonor de Áustria, em Lisboa, em 1521, cuja "ordenança" Gil Vicente tinha a cargo: fogo de artifício, jogos, desfiles navais, doze cadafalsos com teatro e demais "envenções". Nessa reconstituição, o autor glosa a informação de Gaspar Correia, pecando, por defeito, na leitura de algumas passagens. A título de exemplo, da descrição de uma representação no lado direito da Porta da Oura, "...onde andava um doutor vistido em ũa opa de veludo roxo que the distrinçou a tenção da representação", infere: "A única personagem com falas neste auto é um doutor (também vestido de roxo como o doutor Diogo Pacheco e o bedel da Universidade), cuja intervenção parece corresponder à da nomeação das figuras" (pp. 3940). Ora, "tenção" significa também forma dialogada, pelo que, em meu entender, as falas do doutor podem não estar confinadas à nomeação de figuras, acumulando a função de apresentar o argumento do diálogo'.

A partir da p. 46, analisa-se a procissão do Corpo de Deus, um espectáculo em movimento de que fazem parte elementos alusivos ao teatro: aparatos cénicos, figuração de personagens isoladas, ou em contracena, e autos em espaços delimitados. Acerca destas duas festas, sintetizase: "As procissões e as entradas régias correspondem às duas principais manifestações públicas espectaculares e com preparação prévia dos séculos XV e XVl" (p. 57).

$\mathrm{Na}$ continuidade da caracterização do universo imagético da época, merecem também destaque as iniciativas de D. Manuel I no sentido de inscrever as suas insignias na produção artística, que procurava controlar, com vista a uma eficaz difusão do poder real. Em falta, fica a referência a D. João III, do qual nada nos é dito no domínio desta temática, apesar de parte da actividade teatral de Gil Vicente ter ocorrido no seu reinado. 0 poder régio também determina o estatuto das artes ${ }^{3}$, impondo diferenças entre pintura e arquitectura. Na 4 a secção deste capitulo, dá-se conta de como a primeira surge imersa no 


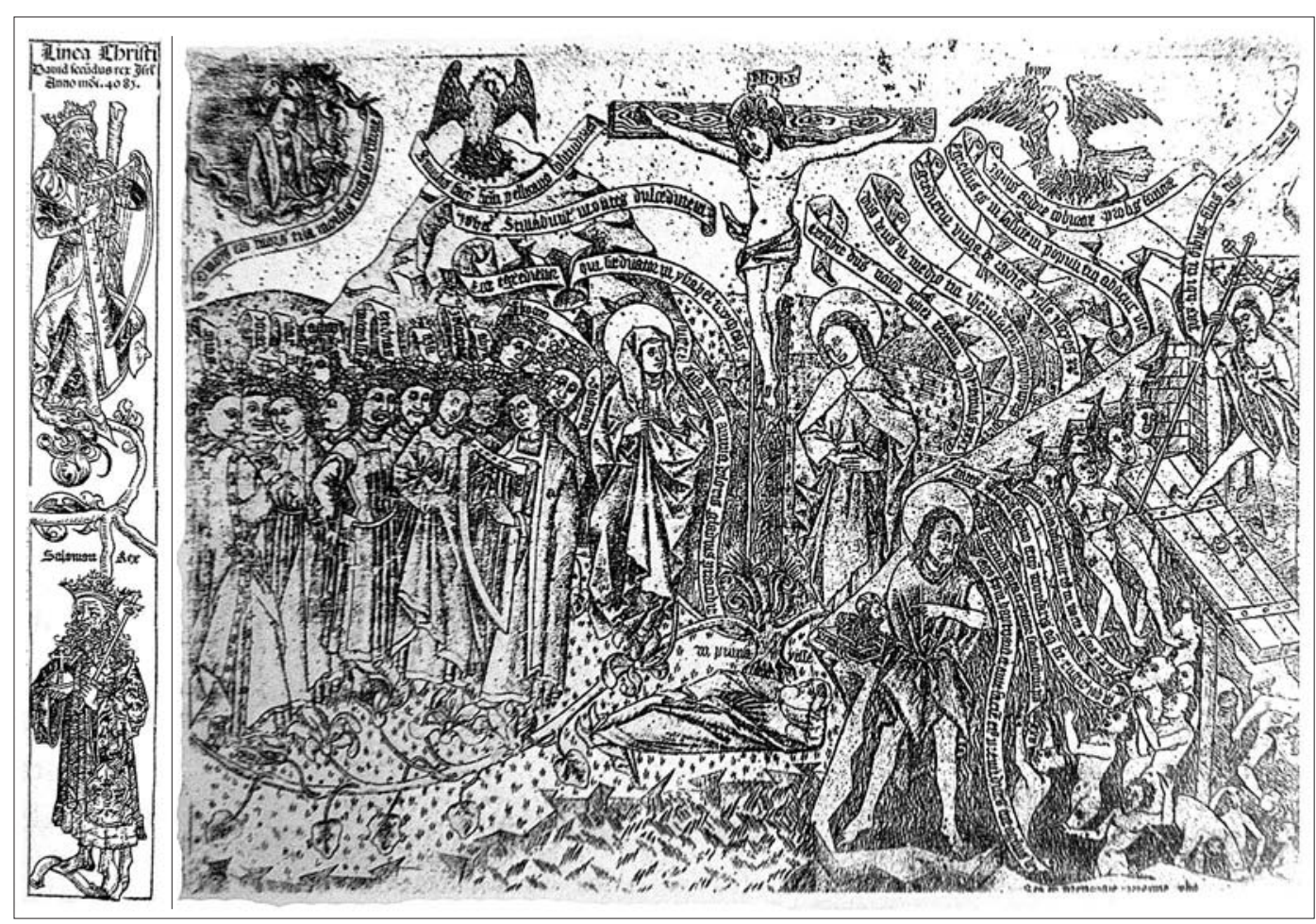

corporativismo, enquanto a segunda resgata individualidades. Gil Vicente, inserido neste contexto, é nomeado em 1524 "Mestre de retórica das representações", recebendo rendimentos fixos pela actividade teatral e consolidando o seu prestígio (p. 84). É inegável o incremento da actividade artística nos reinados de D. Manuel I e D. João III, o que, como é atestado na secção seguinte, originou a procura de obras de arte no exterior, principalmente na Europa do Norte, no reinado do primeiro, e maioritariamente sob a influência de Itália, no caso do segundo. Os critérios avaliativos que, à época, condicionavam a recepção das obras são isolados na última secção do capítulo: a capacidade de comover, o carácter de novidade e o registo "natural" conjugavam-se na excelência (pp. 112-114).

0 terceiro e último capitulo (pp. 129-195) é composto por sete secções: "Metodologia", "As figuras em desfile", "Anjos", "Diabos", "Uma alegoria da vida", "Justos" e "Uma acção num espaço". Consiste na leitura iconológica de História de Deos, "um desfile processional de figuras", acerca do qual se conjectura, a priori com excessivo optimismo, o "aparente sucesso editorial" (p. 132), por ser dos poucos textos vicentinos (como Barca do Inferno, Inês Pereira, Maria Parda e Fé) a gozar de uma edição quinhentista avulsa, fora da Copilação. Contudo, se juntarmos a essa edição avulsa da Biblioteca Nacional de
Madrid, um novo folheto ${ }^{4}$, da Biblioteca dos Marqueses singulariza-se como o único auto de Gil Vicente de que se conhecem dois folhetos quinhentistas.

Metodologicamente, são definidos campos de pesquisa acções. Quer episódios representados, como a descida de Cristo ao limbo, quer invocados, como a crucificação, a par com a introdução de figuras, como o Anjo, a Morte e David, facilmente reconhecíveis pelo público da época, fazem uso da familiaridade da audiência com a produção imagética coeva, permitindo, a posteriori, colocar hipóteses acerca da componente espectacular da letra dos autos. Algumas das possiveis fontes iconográficas do auto são identificadas: A Redenção do mundo pela morte de Cristo na cruz, gravura do Mestre das Filacteras ou Mestre de 1464 (imagem 23, p. 106); Melancolia I, gravura de Albrecht Dürer, 1514 (imagem 35, p. 140); a Crónica de Nuremberga, de Hartmann Schedel, gravuras de Wohlgemuth, 1493 (imagem 42, p. 158), etc.

Não obstante a grande acuidade de alguns passos da análise efectuada, nomeadamente, quando evidencia o potencial cénico de uma rubrica como "Toca Satanás a Job e fica coberto de lepra"5 (p. 172) e coloca hipóteses acerca do espaço da representação (pp. 184-195), há de Sabugosa e Condes de São Lourenço, História de Deos iconográfica, que contemplam figuras, trajes, adereços e
David e Salomão, Crónica de Nuremberga de Hartmann Schedel, gravuras de Wohlgemuth, 1493, fólio 47 v., gravura.

A redenção do mundo pela morte de Cristo na cruz, Mestre das Filacteras ou Mestre de 1464, gravura.

${ }^{4}$ História de Deos e Ressurreição de Cristo, António Álvares, 1598. Informação recolhida de As obras de Gil Vicente, direcção cientifica de José Camões, Vol. IV, Lisboa, edição do Centro de Estudos de Teatro e Imprensa Nacional-Casa da Moeda, 2002, p. VIII. 
Melancolia I, de Albrechi Dürer, 1514, gravura.

${ }^{5}$ Edição op. cit., Vol. I, p. inferências a carecer de explicação: "Os patriarcas entram no limbo cada um por sua vez a mando da Morte, primeiro Isaías, depois Abraão, Moisés e, finalmente, o rei David" (p. 177). A verdade é que não consigo localizar em História de Deos qualquer indicação acerca do modo como as ditas figuras dão entrada no limbo.

Os dois alicerces deste estudo, a bibliografia e a colecção de imagens, poderiam ter merecido outro tratamento. A primeira (pp. 203-221), exaustiva e directamente proporcional à documentação convocada, justificaria um indice remissivo de autores, de modo a autorizar a consulta de informação específica, critério à margem da Tese mas que, em contrapartida, acrescentaria versatilidade ao livro. A segunda, disseminada ao longo da obra, num insuficiente preto e branco, nem sempre oferece a melhor qualidade, em termos de reprodução, o que, face à temática deste trabalho, não é de somenos. No entanto, a maior dificuldade é a rara coincidência de página entre texto e imagem para que remete, sem que o leitor seja informado da página em que, de facto, se encontra (na p. 63 alude-se à imagem n॰17 que só surge na p. 100; na p. 135 descreve-se a n॰23 da p. 106; na p. 139 refere-se a n 10 que está na p. 73, etc.). Poder-se-ia ter incluído, além do número de ordem da imagem, a respectiva página. Outra hipótese seria as imagens surgirem no final, em Anexo, devidamente ordenadas, ou, ainda mais arrojado, à semelhança do que se verifica na Tese, coligidas num CD-ROM.

Na passagem de uma Tese a livro, há que atender a um público mais vasto e, simultaneamente, menos especializado, a quem se endereça a matéria de leitura. Neste caso, a transposição, porventura, demasiado directa, faz-se sentir ao nível da organização da informação. Por exemplo, da p. 92 à p. 105, no âmbito da secção "Círculos de informação", consagrada às influências do exterior na produção artística portuguesa da primeira metade do século XVI, revêem-se, cronologicamente, os principais estudos acerca das fontes iconográficas do teatro de Gil Vicente, emergindo nomes como Paulo Quintela, I. S. Révah, Fernando Moser, Mário Martins, etc. Este enquadramento teórico caberia melhor num capítulo introdutório, ao permitir recuperar parte da génese da investigação.

Para futuras corrigendas, dou conta da existência da indicação da nota 327 (p. 139), sem que Ihe corresponda uma nota efectiva ${ }^{6}$, reportando-me ainda a alguns aspectos de carácter formal:

a) uso não uniformizado de maiúsculas e minúsculas (cf. notas 134 e 135, p. 58, na primeira, surge "Parte IV" na indicação bibliográfica que a compõe e na segunda

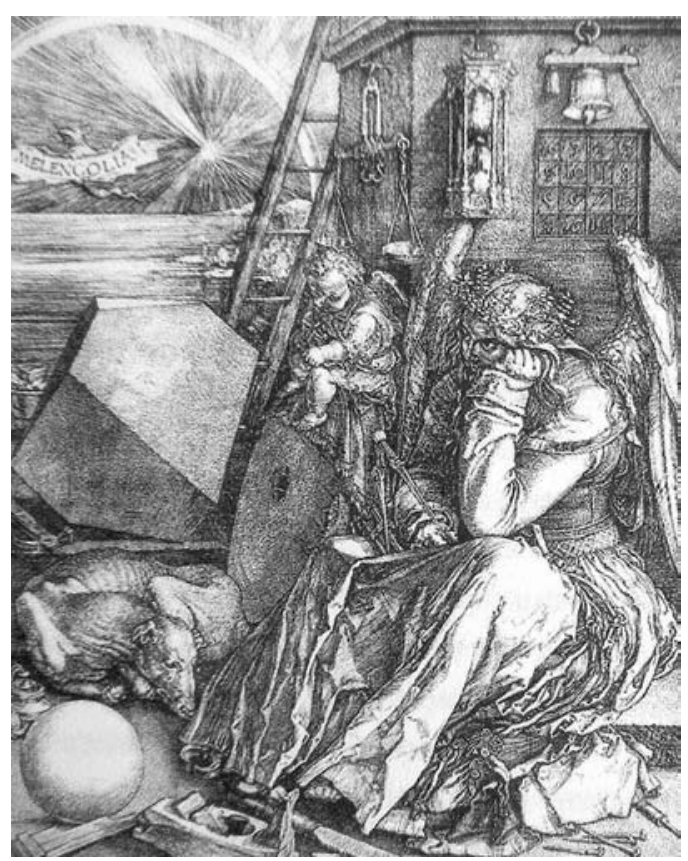

deparamos com "parte III"; na p. 82 "frei Braz" e na p. 91 "Frei João Claro");

b) alternância, aparentemente arbitrária, entre formas acentuadas e não acentuadas (nas pp. 124-125 "0 Jupiter de Cortes obedece à Providência por mando de Deus; o Júpiter de Quatro Tempos...");

c) inobservância dos critérios de actualização ortográfica dos textos citados, expressos na p. 17 (de entre numerosos casos, cf. p. 44, "qando Ih'a prouvesse" por "quando Ih' aprouvesse"; p. 53, na qual ocorrem formas como "Irá" e "possivel", a par com "decencia", para além da falta de itálico, a assinalar devidamente o final da citação; p. 69, coexistência de formas como "arvores", "lioes", "bufaros", "jóias" e "pés").

Para concluir, este é um trabalho que se afigura pioneiro, na consistência metodológica que alcança entre História do Teatro e História da Arte, e ao qual se aplicam ipsis verbis as palavras do próprio autor, a propósito da Crónica de Gaspar Correia: " ...passamos a ter uma memória das imagens que o teatro produziu, o que o torna num documento único para a História do Teatro daquele periodo" (p. 28). 